\title{
Hydrophobicity and molecular weight of humic substances on ultrafiltration fouling and resistance
}

\author{
Chien-Hwa $\mathrm{Yu}^{\mathrm{a}}$, Chung-Hsin $\mathrm{Wu}^{\mathrm{b}, *}$, Chia-Hung Lin ${ }^{\mathrm{c}}$, Chi-Hung Hsiao ${ }^{\mathrm{c}}$, Cheng-Fang Lin ${ }^{\mathrm{c}}$ \\ a Department of Leisure and Recreation Administration, Ming Chuan University, Taoyuan, Taiwan, ROC \\ ${ }^{\mathrm{b}}$ Department of Environmental Engineering, Da-Yeh University, 112, Shan-Jiau Road, Da-Tsuen, Chang-Hua, Taiwan, ROC \\ ${ }^{\mathrm{c}}$ Graduate Institute of Environmental Engineering, National Taiwan University, Taipei, Taiwan, ROC
}

\section{A R T I C L E I N F O}

\section{Article history:}

Received 12 March 2008

Received in revised form 6 September 2008

Accepted 4 October 2008

\section{Keywords:}

Hydrophobicity

Molecular size

Ultrafiltration

Humic substances

Fouling

\begin{abstract}
A B S T R A C T
Humic substances are the major foulant during ultrafiltration (UF) of wastewater. This study evaluates the effects of hydrophobicity and fractionated humic substances on UF fouling and permeation resistance. A commercial humic acid (HA) obtained from Aldrich was subjected to DAX-8 resin for fractionation of hydrophobic and hydrophilic fractions. These fractions were fractionated further into different molecular weight groups using gel filtration chromatography. The hydrophilic fraction exhibited the greatest flux decline, revealing that hydrophobicity decreases fouling. Since the size of particle fractions was significantly smaller than the pore size of membranes, fouling was greatest for the largest fraction with a 100-kDa membrane and the smallest fraction with a $10-\mathrm{kDa}$ membrane. Severe fouling was due to adsorption and pore blocking. For the first $300 \mathrm{~min}$ of filtration, the fouling rate was high in all fractions and is more for $100-\mathrm{kDa}$ than $10-\mathrm{kDa}$ membrane due to greater hydraulic resistance of the HA deposit on the membrane surface. The effect of resistances was also investigated. Each operationally defined resistance depended on membrane pore size, pressure, and HA characteristics. For hydrophobicity and the molecular weight effect, the hydrophilic fraction has the strongest resistance. This study suggested that strong resistance is responsible for irreversible fouling and that is primarily due to pore adsorption and pore blocking.
\end{abstract}

(C) 2008 Elsevier B.V. All rights reserved.

\section{Introduction}

Membrane technology is widely utilized for water and wastewater treatment, and in food, chemical, and pharmaceutical industries because of the technology's high removal capability and ability to meet multiple treatment objectives. The use of membranes in wastewater treatment technology has received considerable attention due to modified membrane characteristics, reduced membrane cost and their ability to remove different contaminants. For instance, different membrane systems have been applied for byproduct disinfection by removing organic precursors [1,2], and include the use of ultrafiltration (UF) for removing natural organic matter (NOM) [3-6]. However, one primary barrier to increased use of membrane technology is membrane fouling.

Generally, the fouling and the resultant flux decline are affected by membrane type, feed characteristics and operating conditions. Among membrane characteristics, pore size [7], pore size distribution [8], charge [9], hydrophobicity [10] and roughness [11] all affect the degree of membrane fouling. Wastewater characteristics, which

\footnotetext{
* Corresponding author. Tel.: +886 5 5347311; fax: +88655334958.

E-mail address: chunghsinwu@yahoo.com.tw (C.-H. Wu).
}

interact with a membrane, also play a key role in membrane fouling. These characteristics include ionic strength [12], $\mathrm{pH}$ [1], presence of divalent ions [5], hydrophobicity of a particular compound [3] and size of solutes [13]. For operating conditions, temperature, pressure, $\mathrm{pH}$ [14], feed rate and influent contaminant concentration all influence permeate flux [15].

Humic substances (HSs) are a major part of NOM. Membrane fouling by HSs is a primary factor limiting pressure-driven membrane processes such as UF. Fouling caused by humic acid (HA) is influenced mainly by characteristics of the HSs and membrane, hydrodynamic conditions and the chemical composition of feed water [16].

Ultrafiltration membranes have been widely examined in removing NOM from drinking water sources. Previous studies have indicated that electrostatic interactions and solute transport properties, such as mass transfer coefficient, influence membrane performance [17,18]. Cho et al. [3] revealed that even a loose negatively charged UF membrane with a molecular weight cutoff (MWCO) value of approximately 8000 could be applied to remove low-weight (ca. 2000) macromolecular NOM. The concept of an effective MWCO has been introduced in several studies to account for enhanced NOM removal behavior of a negatively charged membrane under the same hydrodynamic operational conditions. 
Considerable disagreement exists about fouling mechanisms and the extent of the effects of hydrophobicity of a substrate on membrane fouling [14]. Is the flux decline proportional to membrane pore size? Is the hydrophilic portion of a substrate responsible for membrane fouling? What is the effect of membrane pressure on permeate flux? To what extent is fouling reversible? Clearly, a systematic study is required to address these questions. Consequently, this study quantifies the fouling phenomenon as a function of HA characteristics, with respect to HA hydrophobicity and molecular size on UF performance. A commercial humic substance was fractionated into hydrophobic and hydrophilic fractions, as well as fractions with different molecular weights. Specifically, factors associated with UF pore size ( 10 and $100 \mathrm{kDa}$ ) and operating transmembrane pressures $(100-240 \mathrm{kPa})$ were varied to determine their effects on the permeate flux of these fractions. An operationally defined flux resistance was then utilized to provide a flux decline percentage (final flux divided by initial flux) and to calculate the following parameters: intrinsic resistance $\left(R_{\mathrm{m}}\right)$; weak resistance $\left(R_{\mathrm{wa}}\right)$; strong resistance $\left(R_{\mathrm{sa}}\right)$; and, reversible resistance $\left(R_{\mathrm{r}}\right)$.

\section{Materials and methods}

\subsection{Samples}

Approximately $1 \mathrm{~g}$ of commercial HA (Aldrich, sodium salt) was initially dissolved in Milli-Q water, filtered through a $0.45-\mu \mathrm{m}$ filter and stored at $4{ }^{\circ} \mathrm{C}$. The stock solution was further diluted to dissolved organic carbon (DOC) of $2 \mathrm{mg} / \mathrm{L}$, the $\mathrm{pH}$ adjusted to 7 $\left(10^{-3} \mathrm{M} \mathrm{Na}_{2} \mathrm{HPO}_{4}\right.$ buffer) and conductivity of $1 \mathrm{mS} / \mathrm{cm}$ (with $\mathrm{NaCl}$ added) prior to use. Additionally, the concentrated HA sample $(1 \mathrm{~g} / \mathrm{L})$ was fractionated into hydrophobic and hydrophilic fractions using DAX-8 resin (Supelite), based on the procedures described by Thurman and Malcolm [19]. The detailed procedures are outlined elsewhere [12]. Briefly, the hydrophilic fraction was collected with acidified $\mathrm{HA}(\mathrm{pH} 2)$ and the hydrophobic fraction was obtained with $0.1 \mathrm{~N} \mathrm{NaOH}$ eluent. Overall recovery factor was approximately $92 \%$.

As explained in Lin et al. [20], the HA solution was fractionated into four groups - G1, G2, G3 and G4 - each with different apparent molecular weights (AMWs) using gel filtration chromatography (GFC). Briefly, Sephadex G-75 (Pharmacia) was used as a column packing material; polyethylene glycol was used for calibration of AMWs of $0.4,1.5,6,12$ and $20 \mathrm{kDa}$; blue dextrans (Pharmacia) was employed as an eluent to determine column bulk void volume. The recovery for the fraction by GFC was roughly $95 \%$. The AMW fraction of G1 (8.6-33.4 kDa), G2 (2.2-8.6 kDa), G3 (0.56-2.2 kDa) and G4 (0.14-0.56 kDa) was $37 \%, 24 \%, 27 \%$ and $12 \%$, respectively.

\subsection{UF system}

The negatively charged polysulfone hollow fiber membrane (inner diameter, $1.0 \mathrm{~mm}$; thickness, $0.25 \mathrm{~mm}$; length, $25 \mathrm{~cm}$; surface area, $\left.7.8 \mathrm{~cm}^{2}\right)(\mathrm{A} / \mathrm{G}$ Technology $\mathrm{Co}$.) was operated in a cross-flow mode. The $\mathrm{N}_{2}$ cylinder was employed to provide feed pressure; pressure gauges were placed at the inlet and retentate exit points (Fig. 1). The membrane was initially washed with alcohol at $70 \mathrm{kPa}$ inlet pressure for $5 \mathrm{~min}$ and then rinsed with distilled water for $8 \mathrm{~h}$ prior to use.

The DOC rejection $(R, \%)$ is defined as [1]:

$R=\left(1-\frac{C_{\mathrm{p}}}{C_{\mathrm{f}}}\right) \times 100$

where $C_{\mathrm{p}}$ and $C_{\mathrm{f}}$ are permeate and feed DOC concentrations, respectively.

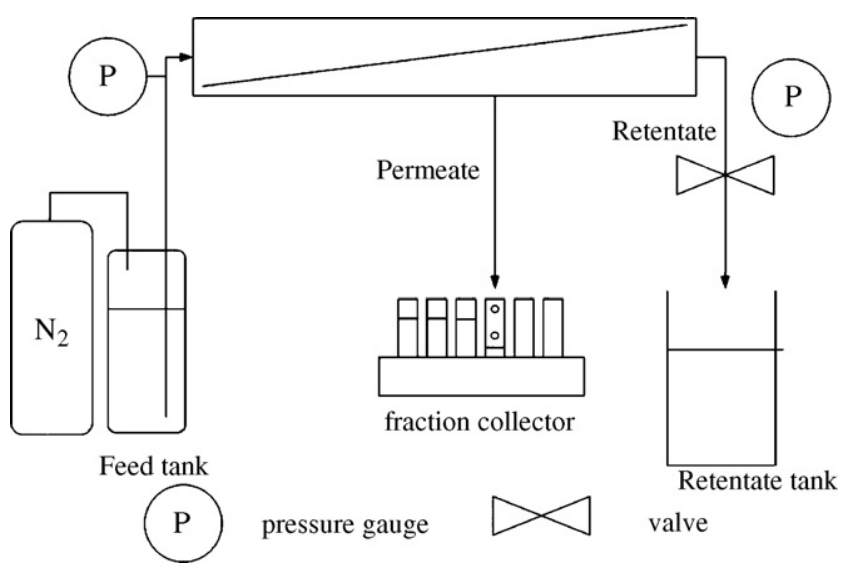

Fig. 1. Schematic of UF operation.

\subsection{Experiments}

Two membrane pore sizes ( 10 and $100 \mathrm{kDa}$ ) and three transmembrane pressures $(100,170$ and $240 \mathrm{kPa}$ ) were evaluated at a constant $\mathrm{pH}(7.0 \pm 0.1)$, influent DOC concentration $(2 \mathrm{mg} / \mathrm{L})$ and ionic strength $(1 \mathrm{mS} / \mathrm{cm})$ for three samples (unfractionated, hydrophobic and hydrophilic fractions). In total, 18 experiments were conducted. For the AMW study, only two pressures (100 and $170 \mathrm{kPa})$ at a constant ionic strength $(300 \mu \mathrm{S} / \mathrm{cm})$ and $\mathrm{pH} 7$ were employed. During the 24-h UF operational period, the permeate was collected periodically for DOC analyses. Influent and retentate rates were measured to determine the permeate rate.

\subsection{Resistance}

The operationally defined resistances include $R_{\mathrm{m}} ; R_{\mathrm{wa}} ; R_{\mathrm{Sa}}$ and $R_{\mathrm{r}}$. The premise of resistance is based on the assumption that $R_{\mathrm{r}}$, which forms via a polarization layer and gel formation, can be eliminated by water washing alone. The $R_{\text {wa }}$, which formed due to weak adsorption of the component present in the feed on the membrane, can be reduced with chemical cleaning, whereas $R_{\mathrm{sa}}$ remains after chemical cleaning. A similar approach was used by Cho et al. [21].

The $R_{\mathrm{m}}$ of the membrane was first determined by determining the membrane permeate flux $(\mathrm{J}, \mathrm{m} / \mathrm{s})$ with deionized water.

$J=\frac{P_{\mathrm{T}}}{R_{\mathrm{m}}}$

where $P_{\mathrm{T}}$ is transmembrane pressure (Pa) and $R_{\mathrm{m}}$ in N s $/ \mathrm{m}^{3}$.

The flux after UF operation at a constant rate $(5 \mathrm{~mL} / \mathrm{min}$ or velocity of $0.12 \mathrm{~m} / \mathrm{s}$ ) can be expressed as

$J=\frac{P_{\mathrm{T}}}{R_{\mathrm{m}}+R_{\mathrm{r}}+R_{\mathrm{wa}}+R_{\mathrm{sa}}}$

By rinsing the membrane with deionized water at constant flow rate of $5 \mathrm{~mL} / \mathrm{min}$ for $30 \mathrm{~min}$ after UF operation, this study assumed $R_{\mathrm{r}}$ can be eliminated, resulting in a new flux:

$J^{\prime}=\frac{P_{\mathrm{T}}}{R_{\mathrm{m}}+R_{\mathrm{wa}}+R_{\mathrm{sa}}}$

Another new flux was obtained by first rinsing the membrane with $0.1 \mathrm{~N} \mathrm{NaOH}$ solution for $10 \mathrm{~min}$ and then deionized water for $30 \mathrm{~min}$.

$J^{\prime \prime}=\frac{P_{\mathrm{T}}}{R_{\mathrm{m}}+R_{\mathrm{sa}}}$

Consequently, Eqs. (2)-(5) were used to derive the fractions of these different resistances. 


\subsection{Analysis}

The DOC (samples filtering through $0.45-\mu \mathrm{m}$ paper) was measured using a TOC analyzer (O.I. 1010 model). The Fourier transform infrared spectroscopy (FTIR) spectrum of $4000-400 \mathrm{~cm}^{-1}$ was obtained via the $\mathrm{KBr}$ pellet technique on a Nicolet Magna II 550 FTIR spectrometer. The $\mathrm{KBr}$ pellet had a weight ratio of approximately 1:200 (sample/Harshaw Stabilized $\mathrm{KBr}$ ) and was prepared on a Harshaw Model 15 Quick Press. These values appeared to provide good results without noticeable over deconvolution.

\section{Results and discussion}

\subsection{Fraction of hydrophobic/hydrophilic components}

The recovery of commercial $\mathrm{HA}$ into hydrophobic and hydrophilic fractions using XAD-8 resin was roughly $92 \%$ with the majority being the hydrophilic fraction (91\%). Fig. 2 presents the FTIR spectra of different transmittances among three samples of unfractionated HA (Fig. 2a), hydrophobic (Fig. 2b) and hydrophilic fractions (Fig. 2c). Clearly, the peaks of the hydrophobic and hydrophilic fractions differ from those of unfractionated HA. All three forms of HA (Fig. $2 \mathrm{a}-\mathrm{c}$ ) had characteristic peaks in the range of $3000-3500 \mathrm{~cm}^{-1}$ corresponding to $\mathrm{OH}$ stretching vibra-

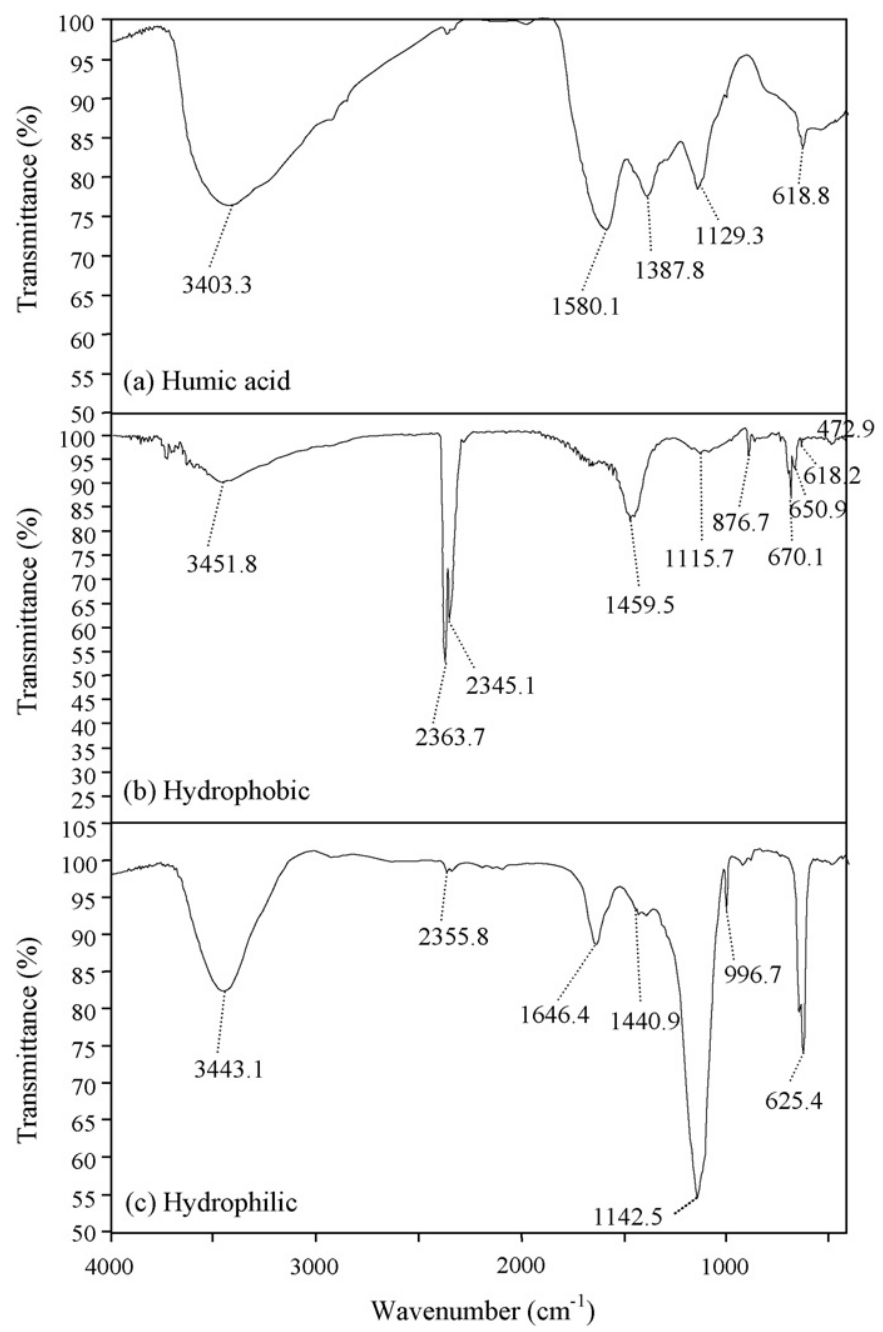

Fig. 2. FTIR profiles (a) humic acid (b) hydrophobic fraction and (c) hydrophilic fraction.

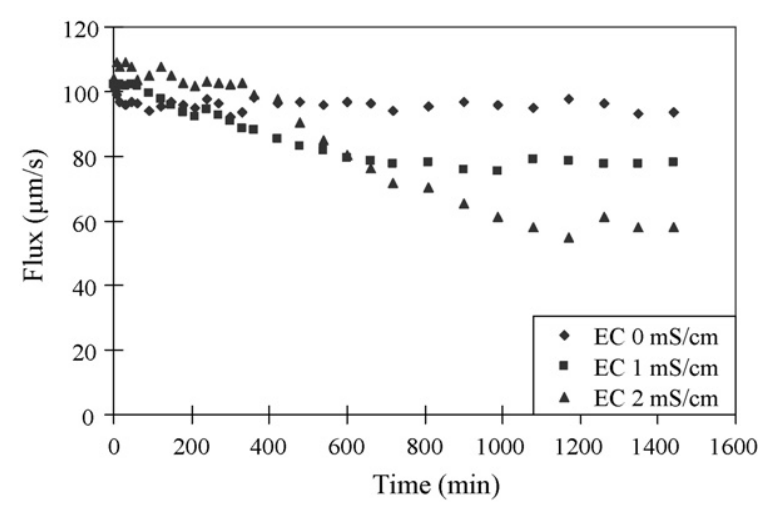

Fig. 3. Absolute flux decline as a function of ionic strength at $170 \mathrm{kPa}$ transmembrane pressure for the $100 \mathrm{kDa}$ membrane size.

tions. These $\mathrm{OH}$ stretching vibrations varied slightly (Fig. 2a-c). The loss of the hydrogen bond in the hydrophobic fraction of HA causes weak $\mathrm{OH}$ stretching vibration. More intensive peak of hydroxyl is formed in hydrophilic fraction may be due to intermolecular hydrogen bonding. The prominent peaks at 1580 and $1387 \mathrm{~cm}^{-1}$ (Fig. 2a), correspond to $\mathrm{COO}^{-}$[22,23], $1646 \mathrm{~cm}^{-1}$ (Fig. 2c) for $\mathrm{C}=\mathrm{O}$ stretching of $\mathrm{COOH}$ and the absence of these corresponding peaks in Fig. $2 \mathrm{~b}$. Similarly, the prominent peak at $1459 \mathrm{~cm}^{-1}$ is primarily due to aromatic part, and clearly indicates fractionation of HA. Moreover, the peak at $1142 \mathrm{~cm}^{-1}$ for the hydrophilic fraction may be due to C-O stretching of esters or ether [24], the hydrophilic fraction has a higher intensive peak than unfractionated HA and hydrophobic fraction, and may be due to esters or ethers.

The UF experiments were performed at a constant DOC of $2 \mathrm{mg} / \mathrm{L}$, conductivity of $1 \mathrm{mS} / \mathrm{cm}$ and $\mathrm{pH}$ of 7 (with $10^{-3} \mathrm{M}$ phosphate buffer). Since $\mathrm{NaOH}$ and $\mathrm{HCl}$ were used in fractionating $\mathrm{HA}$, a relatively high conductivity $(1 \mathrm{mS} / \mathrm{cm})$ was employed. Such high conductivity significantly affects permeate flux. As a blank, this study calculated the flux and flux ratio of water with electrical conductivities of 0,1 and $2 \mathrm{mS} / \mathrm{cm}$ for up to $24 \mathrm{~h}$. The flux decline for $1 \mathrm{mS} / \mathrm{cm}$ conductivity was approximately $25 \%$ after $24 \mathrm{~h}$ (Fig. 3).

As expected, initial flux increased as transmembrane pressure increased (Table 1). Membrane pore size of $100 \mathrm{kDa}$ was larger than some molecules in HA. The initial fluxes for the $100 \mathrm{kDa}$ membrane were markedly higher than those of the $10 \mathrm{kDa}$ membrane. For example, at $240 \mathrm{kPa}$, the initial flux for the hydrophobic fraction for the $100 \mathrm{kDa}$ membrane was $136 \mu \mathrm{m}^{3} / \mathrm{m}^{2} \mathrm{~s}$, and only $95 \mu \mathrm{m}^{3} / \mathrm{m}^{2} \mathrm{~s}$ for the $10 \mathrm{kDa}$ membrane.

Figs. 4 and 5 present the effects of transmembrane pressure on flux decline for hydrophobic and hydrophilic fractions of HA and unfractionated HA for membrane pore sizes of 100 and $10 \mathrm{kDa}$, respectively. Experimental data clearly demonstrate that in all cases, the hydrophilic fraction has the greatest flux decline due to increased fouling. Notably, the hydrophobic fraction and unfractionated HA exhibit a similar flux decline at the highest pressure of $240 \mathrm{kPa}$. As membrane pressure and pore size increase, fouling

Table 1

Initial fluxes of humic acid fractions at different pressures.

\begin{tabular}{lcc}
\hline Pressure $(\mathrm{kPa})$ & Pore size $(\mathrm{kDa})$ & Initial flux $\left(\mu \mathrm{m}^{3} / \mathrm{m}^{2} \mathrm{~s}\right)$ \\
\hline 100 & 100 & $67-79$ \\
& 10 & $40-42$ \\
170 & 100 & $104-107$ \\
& 10 & $59-60$ \\
240 & 100 & $125-136$ \\
& 10 & $88-95$ \\
\hline
\end{tabular}



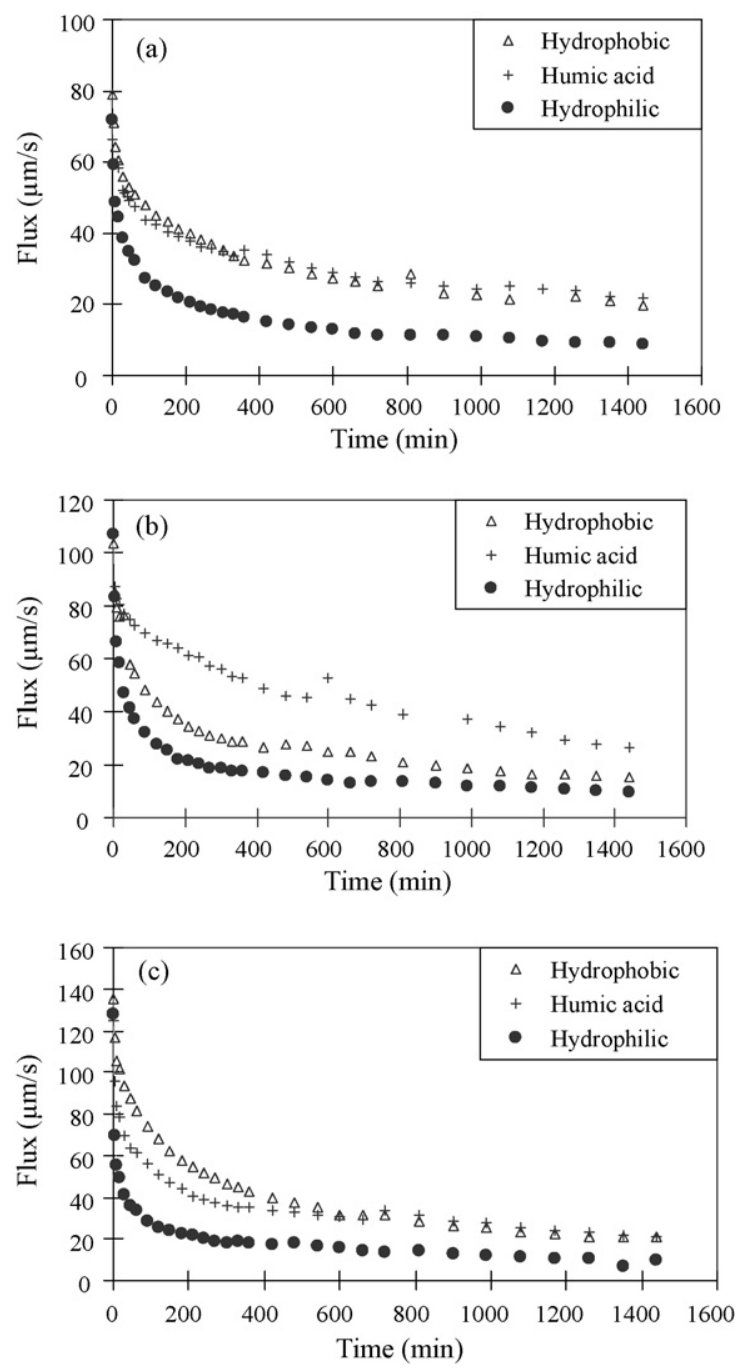

Fig. 4. Absolute flux decline for $100 \mathrm{kDa}$ pore size at different transmembrane pressures. (a) $100 \mathrm{kPa}$ (b) $170 \mathrm{kPa}$ and (c) $240 \mathrm{kPa}$ (DOC $=2 \mathrm{mg} / \mathrm{L}, \mathrm{pH} \mathrm{7}$, and conductivity = $1 \mathrm{mS} / \mathrm{cm}$ ).

increases, resulting in increased flux decline. With increased pressure, the rate of flux decline increases (Fig. $4 a-c$ and $5 a-c$ ). Similarly, for the hydrophilic fraction, the rates of flux decline and fouling increased for the 100-kDa membrane. For hydrophobic and hydrophilic fractions and unfractionated HA, the hydrophilic fraction exhibits severe fouling and accounts for greatest flux decline even through the membrane used was hydrophobic and the reason is mainly attributed by a combination of adsorption and electrostatic attractions. Experimental data clearly suggests that hydrophobicity affects fouling to certain extent only; this finding is consistent with that obtained by Namakura and Matsumoto [25].

Fig. 6 presents the DOC rejection profiles for two different membrane pore sizes at a constant pressure of $100 \mathrm{kPa}$. The DOC rejection pattern for the two sizes was completely different from each other. For a large pore size UF, data are scattered and no trend exists regarding which fraction is removed best by UF (Fig. 6a). However, DOC rejection efficiency increased over time (feed volume). The small molecules of HSs initially passed through the large pores in UF; hence, DOC rejection was reduced. However, over operation for up to $24 \mathrm{~h}$, DOC was eventually rejected due to closed pores, resulting in a rejection rate of about $55 \%$ (Fig. 6a).

For the small pore size (Fig. 6b), the unfractionated HA yielded the highest DOC rejection rate, which was relatively constant
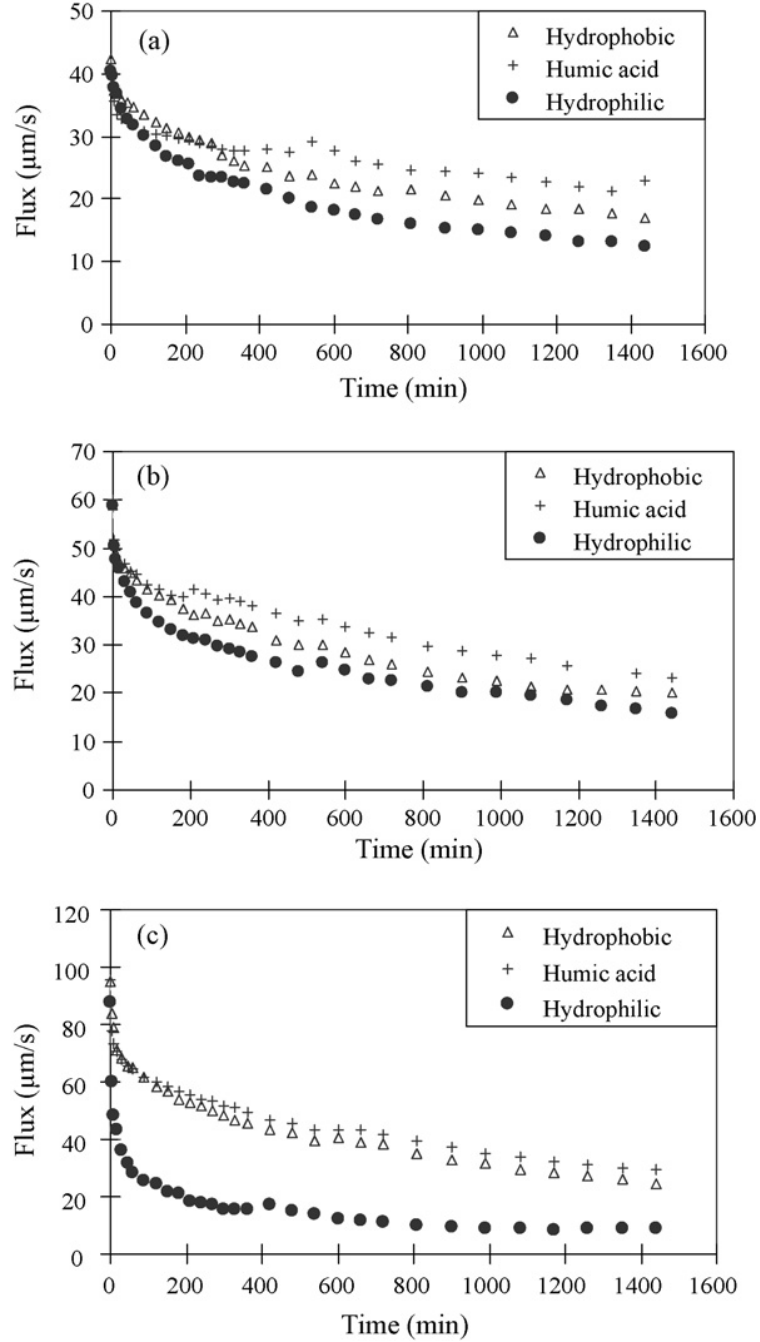

Fig. 5. Absolute flux decline for $10 \mathrm{kDa}$ pore size at different transmembrane pressures. (a) $100 \mathrm{kPa}$ (b) $170 \mathrm{kPa}$ and (c) $240 \mathrm{kPa}$ (DOC = $2 \mathrm{mg} / \mathrm{L}, \mathrm{pH} 7$, and conductivity $=1 \mathrm{mS} / \mathrm{cm})$.

(around 80\%) throughout the experimental run. Such a high DOC rejection rate, however, did not correlate with the flux decline; which, in fact, yielded the smallest flux decline (Fig. 5a). Conversely, DOC rejection of hydrophilic fraction was only about $50 \%$, which exhibited the worst flux decline (Fig. 5a). This experimental finding is same as that obtained by Zularisam et al., [26], who determined that hydrophilic NOM exhibited increased flux decline and less NOM removed due to pore adsorption. The interactions between the hydrophobic membrane and each fraction of HA account for the inability of the membrane to remove DOC.

\subsection{Fraction of apparent molecular weight components}

Fig. 7 shows the absolute membrane fluxes as a function of AMWs of HAs at a transmembrane pressure of $170 \mathrm{kPa}$. Again, the initial fluxes for the small pores were significantly less than those of the large pores (50 versus $183 \mu \mathrm{m}^{3} / \mathrm{m}^{2} \mathrm{~s}$ ) (Fig. 7 legend). For the 10-kDa membrane, the smallest AMW fraction (G4) exhibited the greatest flux decline (Fig. 7a), the small solute may enter into pores resulting in interior pore fouling. This experimental finding was supported by the fact that adsorption increased as solute size decrease [27]. As time progressed, the flux for the largest fraction (G1) declined further, possibly due to exterior pore blockage. 

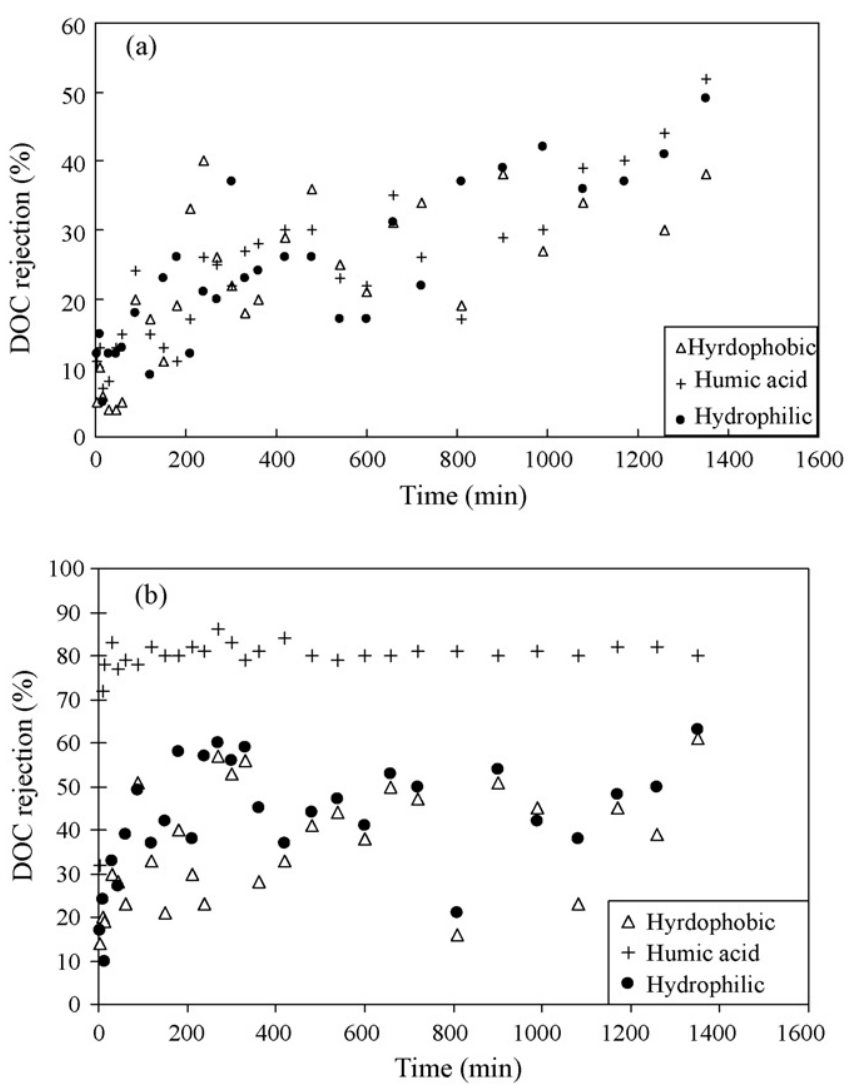

Fig. 6. DOC rejection as a function of membrane pore size at a constant transmembrane pressure $100 \mathrm{kPa}$. (a) $100 \mathrm{kDa}$ and (b) $10 \mathrm{kDa}$.

Notably, unfractionated HA had the smallest flux decline. Conversely, the largest fraction (G1) had the largest flux decline for the $100-\mathrm{kDa}$ membrane (Fig. 7b), whereas the G4 fraction (smallest) had the smallest flux decline. Apparently, the smallest solutes could pass through the large pores. For comparison, the DOC rejection efficiencies for the G4 fraction were approximately $60 \%$ and $80 \%$ for the 100 and $10-\mathrm{kDa}$ membranes, respectively. Notably, the
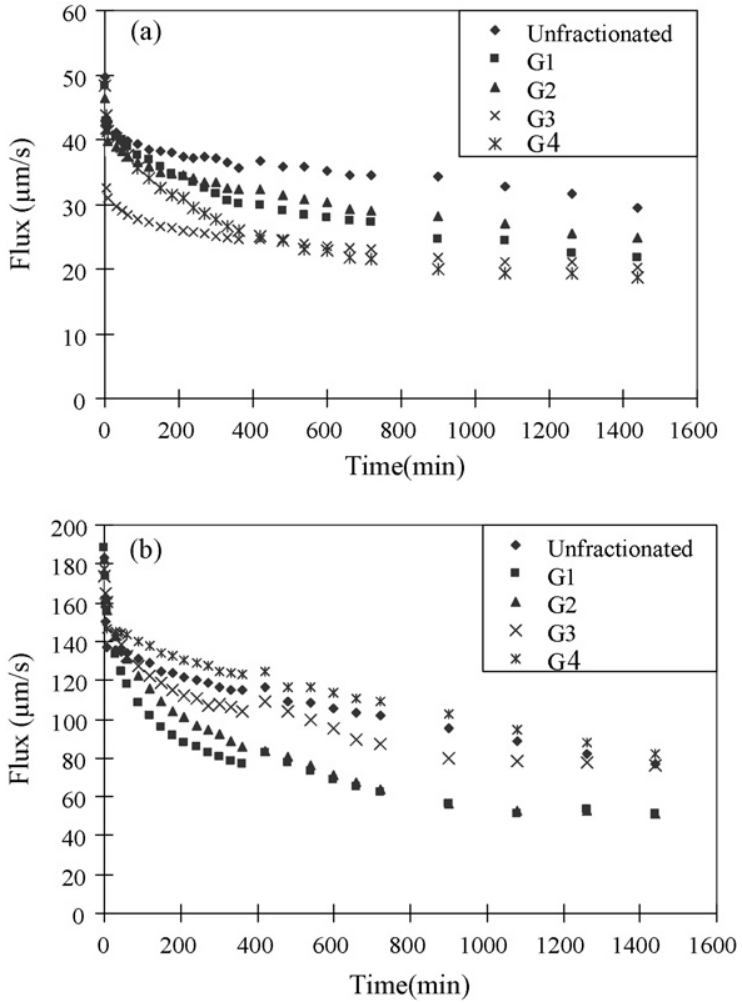

Fig. 7. Absolute flux decline for different membrane sizes at a constant transmembrane pressure $170 \mathrm{kPa}$. The initial fluxes for $100 \mathrm{kDa}$ ranged from 174 to $183 \mu \mathrm{m}^{3} / \mathrm{m}^{2} \mathrm{~s}$ and 46 to $50 \mu \mathrm{m}^{3} / \mathrm{m}^{2} \mathrm{~s}$ for $10 \mathrm{kDa}$ membrane. (a) $10 \mathrm{kDa}$ and (b) $100 \mathrm{kDa}(\mathrm{DOC}=2 \mathrm{mg} / \mathrm{L}, \mathrm{pH} 7$ and conductivity $=300 \mu \mathrm{S} / \mathrm{cm})$.

G4 fraction had a 60\% DOC rejection for the 100-kDa membrane, which is likely due to the aggregation of small particles, thereby resulting in pore adsorption and pore blocking.

As pore size increased, flux decline increased. Only $25 \%$ of the original flux existed after $24 \mathrm{~h}$ for G1 and G2 fractions, whereas about $40 \%$ of the flux remained for G4 fraction (Fig. 7b). Clearly, the interactions between the AMW of HAs and MWCO of the membrane

Table 2

UF resistances of different fractions of humic substances (operation time $=1440 \mathrm{~min}$ ).

\begin{tabular}{|c|c|c|c|c|c|c|}
\hline Membrane pressure & Feed & $R_{\text {total }}\left(\mathrm{N} \mathrm{s} / \mathrm{m}^{3}\right)$ & $R_{\mathrm{m}}(\%)$ & $R_{\mathrm{r}}(\%)$ & $R_{\text {wa }}(\%)$ & $R_{\mathrm{sa}}(\%)$ \\
\hline \multicolumn{7}{|c|}{100 kDa membrane size } \\
\hline \multirow{3}{*}{$100 \mathrm{kPa}$} & Hydrophobic & $5.06 \mathrm{E}+09$ & 25 & 33 & 4 & 38 \\
\hline & Humic acid & $4.56 \mathrm{E}+09$ & 33 & 47 & 8 & 12 \\
\hline & Hydrophilic & $1.14 \mathrm{E}+10$ & 13 & 25 & 17 & 45 \\
\hline \multirow{3}{*}{$170 \mathrm{kPa}$} & Hydrophobic & $1.12 \mathrm{E}+10$ & 15 & 31 & 9 & 45 \\
\hline & Humic acid & $6.38 \mathrm{E}+09$ & 26 & 34 & 14 & 26 \\
\hline & Hydrophilic & $1.74 \mathrm{E}+10$ & 10 & 21 & 20 & 49 \\
\hline \multirow{3}{*}{$240 \mathrm{kPa}$} & Hydrophobic & $1.17 \mathrm{E}+10$ & 15 & 45 & 11 & 29 \\
\hline & Humic acid & $1.16 \mathrm{E}+10$ & 17 & 35 & 11 & 37 \\
\hline & Hydrophilic & $2.42 \mathrm{E}+10$ & 8 & 23 & 9 & 60 \\
\hline \multicolumn{7}{|l|}{10 kDa membrane size } \\
\hline \multirow{3}{*}{$100 \mathrm{kPa}$} & Hydrophobic & $5.86 \mathrm{E}+09$ & 40 & 25 & 2 & 33 \\
\hline & Humic acid & $4.37 \mathrm{E}+09$ & 57 & 16 & 2 & 25 \\
\hline & Hydrophilic & 7.97E+09 & 31 & 27 & 2 & 40 \\
\hline \multirow{3}{*}{$170 \mathrm{kPa}$} & Hydrophobic & $8.5 \mathrm{E}+09$ & 34 & 26 & 8 & 32 \\
\hline & Humic acid & $7.32 \mathrm{E}+09$ & 39 & 32 & 1 & 28 \\
\hline & Hydrophilic & $1.07 \mathrm{E}+10$ & 27 & 27 & 4 & 42 \\
\hline \multirow{3}{*}{$240 \mathrm{kPa}$} & Hydrophobic & $7.01 \mathrm{E}+09$ & 25 & 28 & 3 & 44 \\
\hline & Humic acid & $5.8 \mathrm{E}+09$ & 30 & 14 & 4 & 52 \\
\hline & Hydrophilic & $1.95 \mathrm{E}+10$ & 10 & 44 & 22 & 24 \\
\hline
\end{tabular}




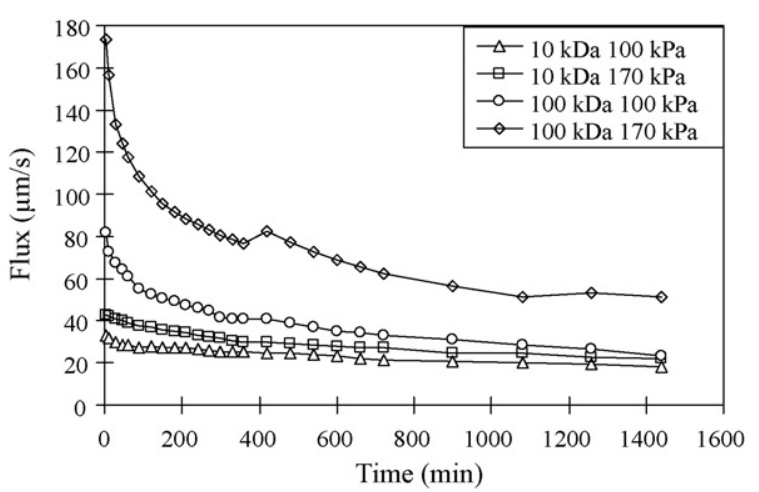

Fig. 8. Absolute flux decline for $\mathrm{G} 1$ fraction as function of membrane size and transmembrane pressures. The initial fluxes for $100 \mathrm{kDa}$ ranged from $91(100 \mathrm{kPa})$ to $188 \mu \mathrm{m}^{3} / \mathrm{m}^{2} \mathrm{~s}(170 \mathrm{kPa})$ and those for $10 \mathrm{kDa}$ from $34(100 \mathrm{kPa})$ to $48 \mu \mathrm{m}^{3} / \mathrm{m}^{2} \mathrm{~s}$ $(170 \mathrm{kPa})(\mathrm{DOC}=2 \mathrm{mg} / \mathrm{L}, \mathrm{pH} 7$ and conductivity $=300 \mu \mathrm{S} / \mathrm{cm})$.

have an important role in membrane fouling. The size of the G1 fraction is smaller than the $100-\mathrm{kDa}$ membrane pore size; hence, fouling was due to pore blockage, gel layer formation and concentration polarization. However, the size of the G1 fraction is equal or greater than the $10-\mathrm{kDa}$ membrane pore size; thus, the fouling mechanism can be explained primarily by gel layer formation and concentration polarization. As Li and Chen [28] stated, severe fouling is caused only by pore blockage and adsorption when compared to fouling by gel layer formations and concentration polarization.

Experimental results were essentially the same for a pressure of $100 \mathrm{kPa}$ (data not shown), with the exception that flux decline was small. Fig. 8 presents the effect of pressure and membrane size for the largest $\mathrm{G} 1$ fraction. A large membrane pore size combined with a high pressure resulted in the highest flux decline and rate of flux decline. The flux decline was negligible for a small pore size combined with a low pressure.

\subsection{Resistances}

The resistances for all conditions were calculated. Table 2 shows the distribution of each fraction for the effect of hydrophobicity. Although, data appear scattered at first glance, a general trend existed in that the hydrophilic fraction accounts for the largest $R_{\mathrm{Sa}}$; the hydrophilic fraction also had the highest flux decline (Figs. 4 and 5). Furthermore, pressure significantly affected the distribution of each operationally defined resistance. Pore size also affected each distribution. For instance, at a constant pressure of $100 \mathrm{kPa}$, the distribution for $R_{\mathrm{r}}$ for $\mathrm{HA}$ increased from $16 \%$ for $10 \mathrm{kDa}$ to $47 \%$ for a loose membrane ( $100 \mathrm{kDa})$.

For a small membrane size ( $10 \mathrm{kDa}), R_{\mathrm{m}}$ was highest for the two low-pressure cases; as pressure decreased, $R_{\mathrm{m}}$ increased. The high ionic strength used $(1 \mathrm{mS} / \mathrm{cm})$ contributes to this high resistance. The $R_{\mathrm{sa}}$ and $R_{\mathrm{r}}$ accounted for most of the remaining fraction with an insignificant contribution from $R_{\mathrm{wa}}$. As the membrane pore size increased, the distribution of the $R_{\mathrm{sa}}$ faction always exceeded that of $R_{\mathrm{m}}$; the molecules of the ionic strength solution passed through the membrane with large pores, reducing $R_{\mathrm{m}}$. A high $R_{\mathrm{sa}}$ fraction indicated that the membrane must be replaced frequently. In short, the membrane resistance of each operationally defined resistance depends on membrane pore size, pressure and the characteristics of HAs.

Fig. 9a and c presents the effects of AMWs on resistance for 10 and $100 \mathrm{kDa}$ membranes at a pressure of $100 \mathrm{kPa}$, respectively. As membrane pore size decreased, membrane resistance $R_{\mathrm{m}}$ increased. Fig. 9b and d plots the resistance of the 10 and $100 \mathrm{kDa}$ membranes, respectively, at a pressure of $170 \mathrm{kPa}$. The total resis-
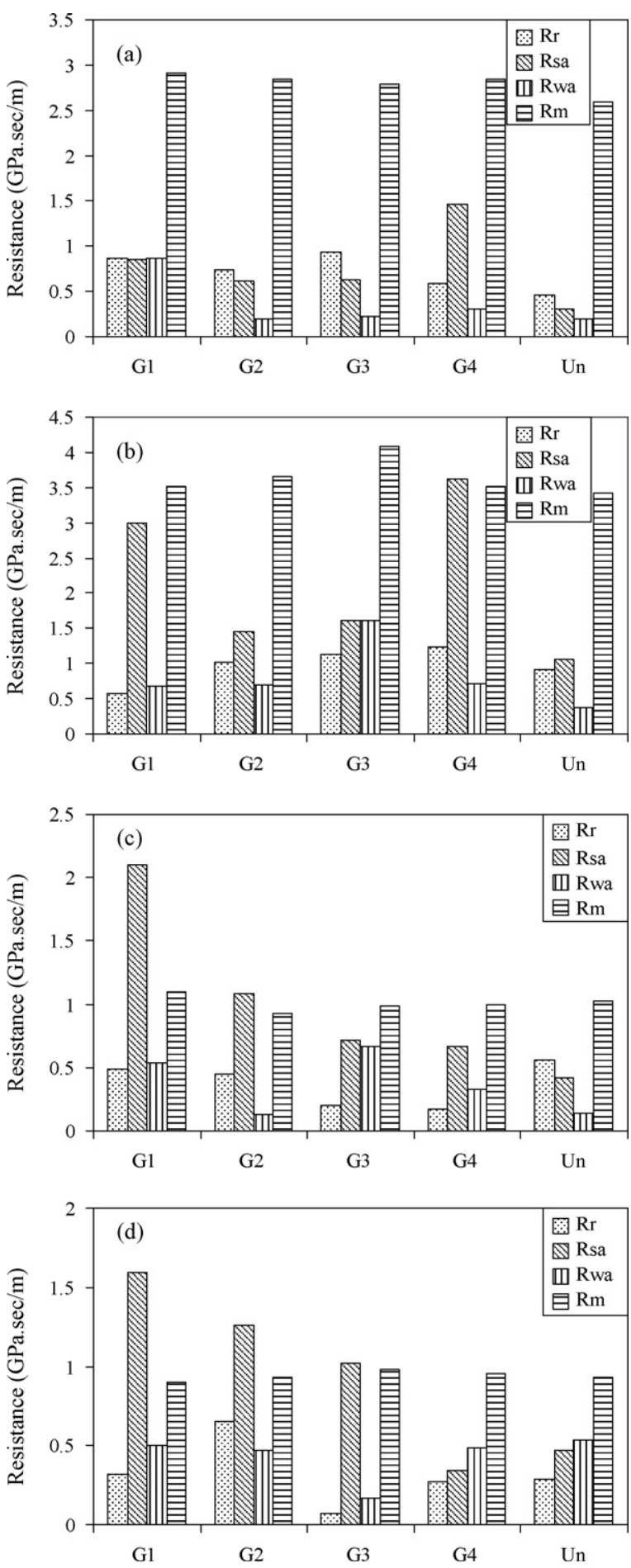

Fig. 9. Resistance distributions as a function of apparent molecular weight. (a) $10 \mathrm{kDa} 100 \mathrm{kPa}$ (b) $10 \mathrm{kDa} 170 \mathrm{kPa}$ (c) $100 \mathrm{kDa} 100 \mathrm{kPa}$ and (d) $100 \mathrm{kDa} 170 \mathrm{kPa}$ $(\mathrm{DOC}=2 \mathrm{mg} / \mathrm{L}, \mathrm{pH} 7$ and conductivity $=300 \mu \mathrm{S} / \mathrm{cm}$ )

tance of the $10 \mathrm{kDa}$ membrane increased with the pressure, (Fig. 9a versus $b$ ), whereas that of the $100 \mathrm{kDa}$ membrane remained roughly constant (Fig. 9c versus d). For the $10-\mathrm{kDa}$ membrane, $R_{\mathrm{sa}}$ was dominant in the G4 fraction. These experimental results are important as strong membrane resistance is probably due to pore adsorption and/or pore blockage. The G1 fraction is responsible for the strong resistance of the 100-kDa membrane. The strong resistance of the $10-\mathrm{kDa}$ membrane is due to the G4 fraction. 


\section{Conclusions}

Humic acid was successfully fractionated into hydrophobic and hydrophilic parts. In both 10 and $100 \mathrm{kDa}$ membranes and at all pressures, the hydrophilic fraction had highest fouling and unfractionated HA was the least, even when the membrane used was hydrophobic. Flux decline is mainly due to the combination of adsorption and electrostatic attractions, suggesting that hydrophobicity affects the fouling only to certain extent. The G4 fraction in the case of the $10-\mathrm{kDa}$ membrane and the $\mathrm{G} 1$ fraction in the case of the 100-kDa membrane had the highest fouling. These fractions are comparatively smaller than respective membranes pore and, hence, severe fouling was caused only by adsorption and pore blockage when compared to fouling by gel layer formations and concentration polarization. The G4 fraction, for which the size is very small compared with the $100-\mathrm{kDa}$ membrane, exhibits some flux decline, which may be due to the formation of aggregates. A large membrane pore size combined with a large pressure generates the highest flux decline and rate of flux decline, and fouling is increased. For a small pore size combined with a low pressure, the flux decline and fouling are negligible. The highest $R_{\mathrm{sa}}$ for the hydrophilic fraction and smallest molecular size fraction in the case of the $10-\mathrm{kDa}$ membrane or largest molecular size fraction in the case of the $100-\mathrm{kDa}$ membrane reveals strong resistance, which is responsible for irreversible fouling due to pore adsorption and pore blocking.

\section{Acknowledgement}

The authors would like to thank the National Science Council of the Republic of China for financially supporting this research under contract no. NSC 95-2221-E-212-022.

\section{References}

[1] J.A. Nilson, F.A. DiGiano, Influence of NOM composition on nanofiltration, J. Am. Water Works Assoc. 88 (1996) 53-66.

[2] S. Lee, J. Cho, Comparison of ceramic and polymeric membranes for natural organic matter (NOM) removal, Desalination 160 (2004) 223-232.

[3] J. Cho, G. Amy, J. Pellegrino, Membrane filtration of natural organic matter: factors and mechanisms affecting rejection and flux decline with charged ultrafiltration (UF) membrane, J. Membr. Sci. 164 (2000) 89-110.

[4] J. Cho, G. Amy, J. Pellegrino, Membrane filtration of natural organic matter: comparison of flux decline, NOM rejection, and foulants during filtration with three UF membrane, Desalination 127 (2000) 283-298.

[5] E. Aoustin, A.I. Schäfer, A.G. Fane, T.D. Waite, Ultrafiltration of natural organic matter, Sep. Purif. Technol. 22-23 (2001) 63-78.

[6] N. Park, Y. Yoon, S.H. Moon, J. Cho, Evaluation of the performance of tight-UF membranes with respect to NOM removal using effective MWCO, molecular weight, and apparent diffusivity of NOM, Desalination 164 (2004) 53-62.
[7] A.R. Costa, M.N. de Pinho, The role of membrane morphology on ultrafiltration for natural organic matter removal, Desalination 145 (2002) 299-304.

[8] C.M. Tam, A.Y. Tremblay, Membranes as fractals: implications and consequences, Desalination 90 (1993) 77-91.

[9] M.R. Wiesner, S. Chellam, The promise of membrane technology, Environ. Sci. Technol. 33 (1999) 360A-366A.

[10] K.K. Malgorzata, M.N. Katarzyna, W. Tomasz, Analysis of membrane fouling in the treatment of water solutions containing humic acids and mineral salts, Desalination 126 (1999) 179-185.

[11] M. Elimelech, X.H. Zhu, A.E. Childress, S.K. Hong, Role of membrane surface morphology in colloidal fouling of cellulose acetate and composite aromatic polyamide reverse osmosis membranes, J. Membr. Sci. 127 (1997) 101-109.

[12] C.F. Lin, T.Y. Lin, O.J. Hao, Effect of humic substances characteristics on UF performances, Water Res. 34 (2000) 1097-1106.

[13] J. Cho, J. Sohn, H. Choi, L.S. Kim, G. Amy, Effects of molecular weight cutoff $\mathrm{f} / \mathrm{k}$ ratio (a hydrodynamic condition), and hydrophobic interactions on natural organic matter rejection and fouling in membranes, J. Water Supply: Res. Technol. 51 (2002) 109-123.

[14] W. Yuan, A.L. Zydney, Humic acid fouling during ultrafiltration, Environ. Sci. Technol. 34 (2000) 5043-5050.

[15] H.M. Yeh, T.W. Cheng, H.H. Wu, Membrane ultrafiltration in hollow-fiber module with the consideration of pressure declination along the fibers, Sep. Purif. Technol. 13 (1998) 171-180.

[16] C. Combe, E. Molis, P. Lucas, R. Riley, M.M. Clark, The effect of CA membrane properties on adsorptive fouling by humic acid, J. Membr. Sci. 154 (1999) 73-87.

[17] A. Braghetta, F.A. DiGiano, W.P. Ball, Nanofiltration of natural organic matter: $\mathrm{pH}$ and ionic strength effects, J. Environ. Eng. 123 (1997) 628-642.

[18] I.C. Escobar, S. Hong, A.A. Randall, Removal of assimilable organic carbon and biodegradable dissolved organic carbon by reverse osmosis and nanofiltration membranes, J. Membr. Sci. 175 (2000) 1-17.

[19] E.M. Thurman, R.L. Malcolm, Preparative isolation of aquatic humic substances Environ. Sci. Technol. 15 (1981) 463-466.

[20] C.F. Lin, Y.J. Huang, O.J. Hao, UF process for removing humic substances: effect of molecular weight fractions and PAC treatment, Water Res. 33 (1999) 1252-1264.

[21] J. Cho, G. Amy, J. Pellegrino, Membrane filtration of natural organic matter: initial comparison of rejection and flux decline characteristics with ultrafiltration and nanofiltration membranes, Water Res. 33 (1999) 2517-2526.

[22] G.L. David, F. Anthonyr, Infrared spectroscopic evidence supporting heterogeneous site binding models for humic substances, Environ. Sci. Technol. 39 (2005) 6624-6631.

[23] A.W. Zularisam, A.F. Ismaila, R. Salim, Behaviours of natural organic matter in membrane filtration for surface water treatment-a review, Desalination 194 (2006) 211-231.

[24] G.R. Aiken, D.M. McKnight, R.L. Wershaw, P. MacCarthy, Humic Acid Substances in Soil, Sediment and Water: Geochemistry, Isolation and Characterization, John Wiley, New York, 1985

[25] K. Namakura, K. Matsumoto, Properties of protein adsorption onto pore surface during microfiltration: effects of solution environment and membrane hydrophobicity, J. Membr. Sci. 280 (2006) 363-374.

[26] A.W. Zularisam, A.F. Ismail, M.R. Salim, M. Sakinah, O. Hiroaki, Fabrication, fouling and foulant analyses of asymmetric polysulfone (PSF) ultrafiltration membrane fouled with natural organic matter (NOM) source waters, J. Membr. Sci. 299 (2007) 99-113.

[27] T. Karanfil, J.E. Kilduff, M.A. Schlautman, W.J. Weber, Adsorption of organic macromolecules by granular activated carbon. 1. Influence of molecular properties under anoxic solution conditions, Environ. Sci. Technol. 30 (1996) 2187-2194.

[28] C.W. Li, Y.S. Chen, Fouling of UF membrane by humic substances: effects of molecular weight and powder-activated carbon (PAC) pre-treatment, Desalination 170 (2004) 59-67. 